\title{
Kinetics of The Autoxidation of Cumene and Tetralin in the Presence of Benzaldehyde*
}

\author{
Tsuneo Ikawa**, Minoru Muto*** and Takashi Shintani***
}

\begin{abstract}
Summary: The autoxidation of cumene and tetralin in the presence of benzaldehyde in the chlorobenzene solvent has been studied kinetically by means of measurements of oxygen absorption. The observed kinetics has been interpreted in the competitive oxidation mechanism postulated by Walling. The decrease and the increase of the overall absorption rate of oxygen with the change of the concentration of hydrocarbon may be explained in the terms of the high reactivity of peroxybenzoic radical and the rate of chain termination.
\end{abstract}

\section{Introduction}

It is known that the addition of a small amount of a substance to be readily oxidized increases the oxidation rate of an organic compound of low reactivity. In recent years, several groups of workers have reported the acceleration of the oxidation rate of $p$-xylene to terephtalic acid by the addition of methylethylketone ${ }^{1)}$ or cyclohexanone ${ }^{2}$, and toluene, $p$-xylene and mesitylene by tertiary alkylbenzene $^{3)}$ or methylcyclohexane ${ }^{3)}$. Kinetics of the co-oxidation has been reported by Walling( ${ }^{4}$, Russell ${ }^{5)}$, Melville ${ }^{6)}$ Alagy ${ }^{7}$, Thomas $^{8>}$ and Howard ${ }^{8)}$. Their studies are on the co-oxidation of the mixture of hydrocarbons and of the mixture of aldehydes.

For cumene oxidation in chlorobenzene we have observed the overall absorption rate of oxygen to fall away with an addition of benzaldehyde in the low concentration of cumene, and rise up in the high concentration of cumene. In order to clear this phenomenon, kinetics of the autoxidation of cumene and tetralin in the presence of benzaldehyde has been investigated.

\section{Experimental}

Commercial benzaldehyde was puried by fractional distillation under nitrogen stream

* Received November 30, 1964.

** Tokyo Institute of Technology, Ōokayama, Meguroku, Tokyo.

*** Tōyō Soda Manufacturing Co., Ltd., Nanyo-cho, Tsuno-gun, Yamaguchi-ken. at $60 \mathrm{mmHg}$ and $99.8-100.3^{\circ} \mathrm{C}$, before its use. Tetralin, cumene and chlorobenzene, in chemical pure, were washed successively with conc. sulfuric acid, dilute alkali and with distilled water, and then dried with calciumchloride. The tetralin was fractionated in the nitrogen atmosphere at $60 \mathrm{mmHg}$ and $121-123^{\circ} \mathrm{C}$, the cumene at $60 \mathrm{mmHg}$ and $75-76^{\circ} \mathrm{C}$ and the chlorobenzene at $760 \mathrm{mmHg}$ and $132-133^{\circ} \mathrm{C}$. No impurities were found on gaschromatogram. Oxygen, purity of $99.9 \%$, was obtained commercially. Schematic diagram of the reaction apparatus is shown in Fig. 1. The oxygen absorption was measured directly with a thermostated gas burette $(1 l)$. The glass reaction vessel (A-type: $45 \mathrm{~mm} \phi \times 150 \mathrm{~mm}$, for the co-oxidation of tetralin and benzaldehyde, B-type: $65 \mathrm{~mm} \phi \times 170 \mathrm{~mm}$, for the

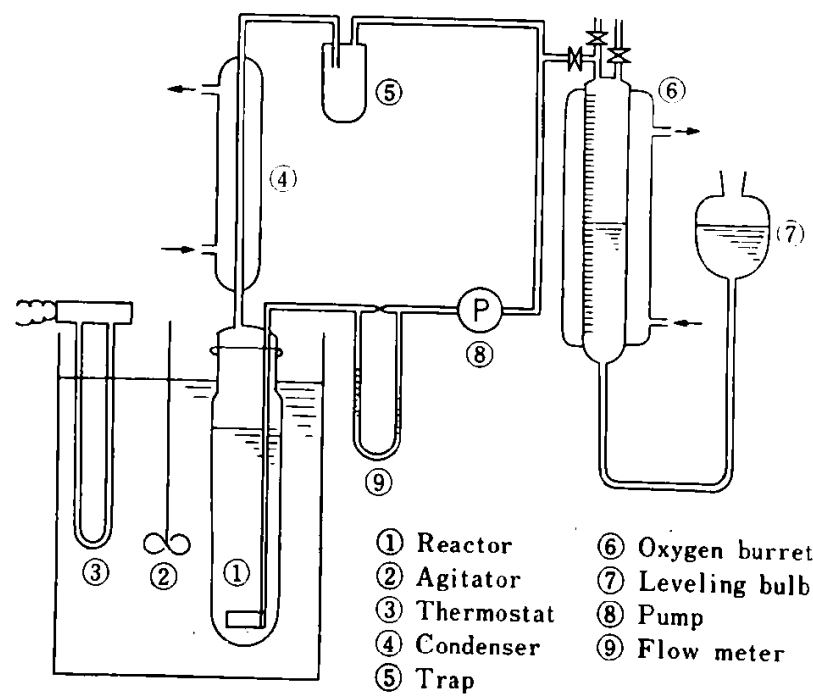

Fig. 1 Apparatus 
Table 1 Reaction conditions and results

\begin{tabular}{|c|c|c|c|c|c|c|}
\hline Run No. & $\begin{array}{c}\text { Temperature } \\
{ }^{\circ} \mathrm{C}\end{array}$ & $\begin{array}{l}\text { Initial concen- } \\
\text { tration of } \\
\text { Benzaldehyde } \\
\text { mole } \cdot l^{-1}\end{array}$ & $\begin{array}{l}\text { Initial concen- } \\
\text { tration of } \\
\text { Tetralin } \\
\text { mole } \cdot l^{-1}\end{array}$ & $\begin{array}{l}\text { Initial concen- } \\
\text { tration of } \\
\text { Cumene } \\
\text { mole } \cdot l^{-1}\end{array}$ & $\begin{array}{l}\text { Absorption rate } \\
\text { of Oxygen } \\
\text { mole } \cdot l^{-1} \cdot \sec ^{-1}\end{array}$ & $k_{7}$ \\
\hline 1 & 64.0 & 1.48 & 0 & & $19.7 \times 10^{-5}$ & \\
\hline 2 & 64.5 & 1.48 & 0.220 & & 2.95 & $5.5 \times 10^{8}$ \\
\hline 3 & 64.0 & 1.48 & 1.47 & & 2.25 & 4.7 \\
\hline 4 & 64.0 & 1.48 & 2.94 & & 1.08 & 160 \\
\hline 5 & 64.0 & 1.48 & 5.15 & & 3.82 & - \\
\hline 6 & 64.0 & 1.48 & 6.25 & & 3.96 & 6.6 \\
\hline 7 & 100 & 0.149 & & 0 & 12.7 & \\
\hline 8 & 100 & 0.149 & & 0.0359 & 6.6 & - \\
\hline 9 & 100 & 0.149 & & 1.07 & 2.7 & $4.4 \times 10^{9}$ \\
\hline 10 & 100 & 0.149 & & 3.58 & 13.0 & 1.2 \\
\hline 11 & 100 & 0.149 & & 5.38 & 14.5 & 3.9 \\
\hline 12 & 100 & 0.149 & & 6.48 & 24.1 & 1.4 \\
\hline 13 & 100 & 0.149 & 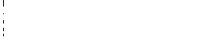 & 7.17 & 26.3 & 1.8 \\
\hline
\end{tabular}

co-oxidation of cumene and benzaldehyde) was immersed in a constant temperature bath. Oxygen was bubbled to the reactor through a porous glass diffuser at a constant high flow rate, about $1 l \cdot \mathrm{min}^{-1}$, to provide a large gas-liquid interface. During an oxygen absorption run, liquid paraffin was admitted from a leveling bulb to the burette as required time to time to keep the oxygen in the reactor at atmospheric pressure.

\section{Results}

Many investigators have proposed the following scheme for the autoxidation of benzaldehyde, tetralin and cumene in the sufficient high oxygen pressure:

$$
\begin{array}{lrl}
\mathrm{RH} \longrightarrow \mathrm{R} \cdot & k_{1} & (1) \\
\mathrm{R} \cdot+\mathrm{O}_{2} \stackrel{\text { very fast }}{\longrightarrow} \mathrm{RO}_{2} \cdot & k_{2} & (2) \\
\mathrm{RO}_{2} \cdot+\mathrm{RH} \longrightarrow \mathrm{RO}_{2} \mathrm{H}+\mathrm{R} \cdot k_{3} & (3) \\
\mathrm{RO}_{2} \cdot+\mathrm{RO}_{2} \cdot \longrightarrow \text { Inert product } &
\end{array}
$$$$
k_{6} \quad(4)
$$

The rate of reaction takes the form:

$$
-\frac{d\left[\mathrm{O}_{2}\right]}{d t}=k_{3} \sqrt{\frac{k_{1}}{k_{6}}}[\mathrm{RH}]^{1.5}
$$

We confirmed that the rate was expressed by equation (5) for the oxidation of benzaldehyde, tetralin and cumene in chlorobenzene at temperatures between $15^{\circ} \mathrm{C}$ and $100^{\circ} \mathrm{C}$ and at concentrations between $0.1 \mathrm{~mole} \cdot l^{-1}$ and 7.2 mole $\cdot l^{-1}$.

By using the absorption rate of oxygen and the values of $k_{3}$ and $k_{6}$ for the oxidations of benzaldehyde, tetralin and cumene as determined by Melville ${ }^{(0,11)}$, Dewar ${ }^{12)}$ and Thomas $^{8)}$, the values of the rate constant $k_{1}$ were calculated to be $2.90 \times 10^{-7} \mathrm{l} \cdot \mathrm{mole}^{-1} \cdot \mathrm{sec}^{-1}$ $\left(64^{\circ} \mathrm{C}, \mathrm{A}\right.$-type reactor) and $8.37 \times 10^{-5} l \cdot \mathrm{mole}^{-1}$. $\sec ^{-1}\left(100^{\circ} \mathrm{C}\right.$, B-type reactor) for benzaldehyde, $\quad 1.27 \times 10^{-9} l \cdot \mathrm{mole}^{-1} \cdot \mathrm{sec}^{-1}\left(64^{\circ} \mathrm{C}\right)$ for tetralin and $2.7 \times 10^{-9} l \cdot \mathrm{mole}^{-1} \cdot \mathrm{sec}^{-1}\left(100^{\circ} \mathrm{C}\right)$ for cumene, respectively. The activation energies of the initial step for the oxidation of benzaldehyde, tetralin and cumene were $11.1 \mathrm{kcal}, 35 \mathrm{kcal}$ and $23 \mathrm{kcal}$, respectively.

The reaction conditions and results of tetralin and cumene in the presence of benzaldehyde in chlorobenzene are summarized in Table 1. As the amount of oxygen absorbed during measurement was not so large, con-

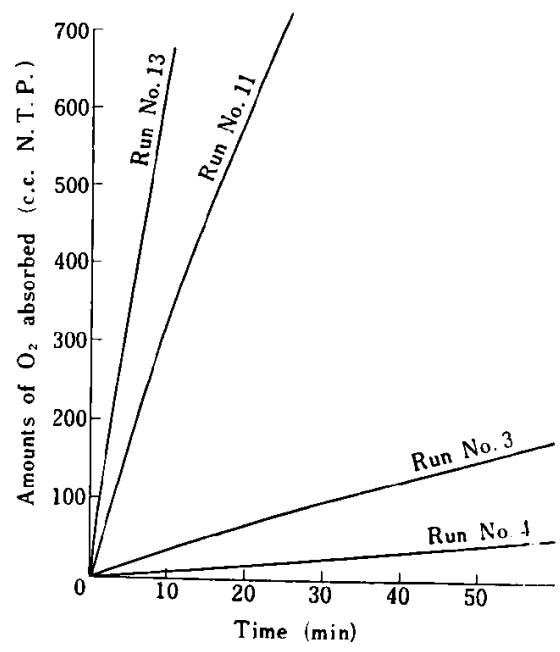

Fig. 2 Oxidation of Binary system 
centration of hydrocarbons and aldehyde could be considered to be constant. Therefore, without the further reaction of peroxides affecting the oxidation rate, the rate was essentially constant. Typical examples of absorption curves are shown in Fig. 2. After the circulation of oxygen for several minutes absorption rates of oxygen became steady-state and the absorption curves showed straight lines. Absorption rate calculated from the slopes of the lines. The absorption rates of oxygen rapidly decreased with the increase of hydrocarbon concentration and then gradually increased. The rate for cumene of 7.17 mole $\cdot l^{-1}$ was about twice as much as the sum of the rate of benzaldehyde without cumene and cumene without benzaldehyde, shown in Fig. 4.

\section{Kinetics}

The scheme for the autoxidation of the mixture of two hydrocarbons in sufficient oxygen pressure is considered as follows ${ }^{4}$ :

$$
\begin{aligned}
& \left\{\mathrm{AH} \longrightarrow \mathrm{A} \cdot \quad k_{1}(6)\right. \\
& \left\{\mathrm{BH} \longrightarrow \mathrm{B} \cdot \quad k_{1}^{\prime}(7)\right. \\
& \left(\mathrm{A} \cdot+\mathrm{O}_{2} \underset{\text { very fast }}{\stackrel{\text { very fast }}{\longrightarrow}} \mathrm{AO}_{2} \cdot \quad k_{2}\right. \text { (8) } \\
& \mathrm{B} \cdot+\mathrm{O}_{2} \stackrel{\text { very fast }}{\longrightarrow} \mathrm{BO}_{2} . \quad k_{2}^{\prime}(9) \\
& \mathrm{AO}_{2} \cdot+\mathrm{AH} \longrightarrow \mathrm{AO}_{2} \mathrm{H}+\mathrm{A} \cdot k_{3} \text { (10) } \\
& \mathrm{BO}_{2} \cdot+\mathrm{BH} \longrightarrow \mathrm{BO}_{2} \mathrm{H}+\mathrm{B} \cdot k_{3}^{\prime}(11) \\
& \mathrm{AO}_{2} \cdot+\mathrm{BH} \longrightarrow \mathrm{AO}_{2} \mathrm{H}+\mathrm{B} \cdot k_{3 \mathrm{~B}}(12) \\
& \mathrm{BO}_{2} \cdot+\mathrm{AH} \longrightarrow \mathrm{BO}_{2} \mathrm{H}+\mathrm{A} \cdot k_{3 \mathrm{~A}}^{\prime}(13) \\
& \left\{\begin{array}{r}
\mathrm{AO}_{2} \cdot+\mathrm{AO}_{2} \cdot \longrightarrow \text { Inert product } \\
k_{6}(14)
\end{array}\right. \\
& \mathrm{BO}_{2} \cdot+\mathrm{BO}_{2} \cdot \cdots, \quad, \quad k_{6}^{\prime}(15) \\
& \mathrm{AO}_{2} \cdot+\mathrm{BO}_{2} \cdot \cdots, \quad, \quad k_{7}
\end{aligned}
$$

We apply this scheme to the oxidation of hydrocarbon in the presence of benzaldehyde, assuming further reaction of hydroperoxide and peracid which affects the oxidation rate does not take place, where, $\mathrm{AH}$ indicates benzaldehyde and $\mathrm{BH}$ stands for tetralin or cumene.

Following equations are applied under steady state conditions:

$$
\begin{gathered}
k_{6}\left[\mathrm{AO}_{2} \cdot\right]^{2}+2 k_{7}\left[\mathrm{AO}_{2} \cdot\right]\left[\mathrm{BO}_{2} \cdot\right] \\
\quad+k_{6}^{\prime}\left[\mathrm{BO}_{2} \cdot\right]^{2} \\
=k_{1}[\mathrm{AH}]+k_{1}^{\prime}[\mathrm{BH}] \\
k_{3 \mathrm{~B}}[\mathrm{BH}]\left[\mathrm{AO}_{2} \cdot\right]=k_{3 \mathrm{~A}}^{\prime}\left[\mathrm{BO}_{2} \cdot\right][\mathrm{AH}]
\end{gathered}
$$

From the speculation described in Discussion, following conditions have been assumed:

$$
k_{3}=k_{3 \mathrm{~B}}, \quad k_{3}^{\prime}=k_{3 \mathrm{~A}}^{\prime}
$$

By solving (17), (18) and (19) simultaneously, and substituting them into the expression for the absorption rate of oxygen, oxygen absorption rate equation of co-oxidation is obtained:

$$
\begin{aligned}
& -\frac{d\left[\mathrm{O}_{2}\right]}{d t} \\
& =k_{1}[\mathrm{AH}]+k_{1}^{\prime}[\mathrm{BH}]
\end{aligned}
$$

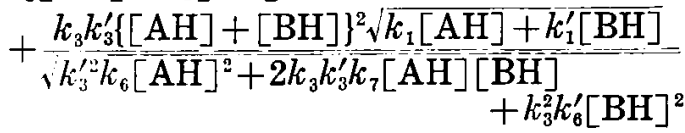

By using values of $k_{1}=2.90 \times 10^{-7}, \quad k_{1}^{\prime}=$ $1.27 \times 10^{-9}, \quad k_{3}=3.38 \times 10^{3}, \quad k_{3}^{\prime}=3.14 \times 10, \quad k_{6}=$ $2.87 \times 10^{8}, k_{6}^{\prime}=2.33 \times 10^{7}$ and observed rates for the co-oxidation of tetralin and benzaldehyde at $64^{\circ} \mathrm{C}$, the values of $k_{7}$ are calculated as shown in Table 1. By using values of $k_{1}=8.37 \times 10^{-5}, \quad k_{1}^{\prime}=2.7 \times 10^{-9}, \quad k_{3}=4.4 \times 10^{3}$, $k_{3}^{\prime}=2.85, \quad k_{\mathrm{\theta}}=3.32 \times 10^{8}, \quad k_{0}^{\prime}=4.56 \times 10^{4} \quad$ and observed rates for the co-oxidation of cumene and benzaldehyde at $100^{\circ} \mathrm{C}$, the values of $k_{7}$ are also calculated and shown in Table 1 . By using values of $k$, above described, and $k_{7}($ mean $)=5.6 \times 10^{8}$ for the co-oxidation of benzaldehyde and tetralin at $64^{\circ} \mathrm{C}$, and $k_{7}$ $($ mean $)=3.2 \times 10^{\circ}$ for the co-oxidation of benaldehyde and cumen at $100^{\circ} \mathrm{C}$, absorption rates of oxygen are calculated, for trial, which are shown in Fig. 3 and Fig. 4, as a function of hydrocarbon concentration. The results agree with the obserbed values.

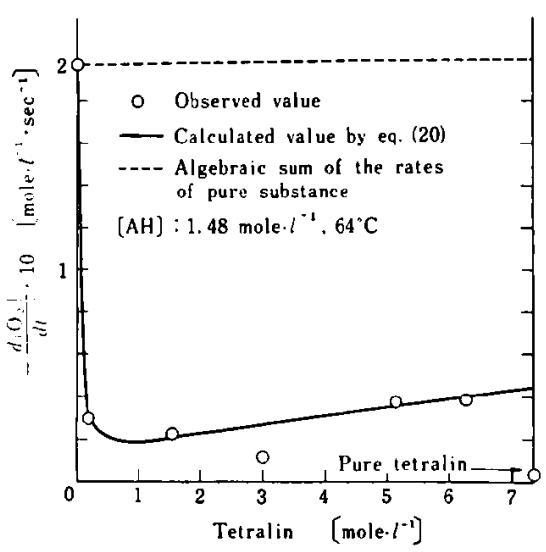

Fig. 3 Rate vs. concentration of Tetralin 


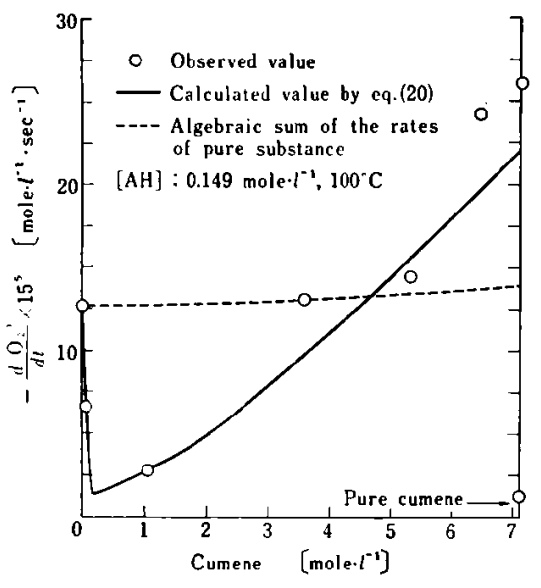

Fig. 4 Rate vs. concentrationgof Cumene

\section{Discussion}

When the decomposition of hydroperoxides and peracid occurs, the reaction mechanism becomes more complex. Under the reaction condition of this study, hydroperoxides are considered to be stable ${ }^{5>}$ during the reaction time and peracid reacts readily with aldehyde to form acid ${ }^{13)}$. This rate constant ${ }^{14}$ is about 200 times as large as that ${ }^{15)}$ for the decomposition of peracid. Addition of cumene hydroperoxide and the oxidized product of benzaldehyde containing perbenzoic acid of 3 mole $\%$ to the oxidation system of the mixture of cumene and benzaldehyde (the concentration of benzaldehyde in reaction mixture was 0.149 mole $\cdot l^{-1}$ ), did not cause any change in the steady-state absorption rate of oxygen. These facts support the assumption that the decomposition and any further reactions of hydroperoxides and peracid affecting the oxidation rate in steady state do not occur.

In a reaction system containing radicals of similar character, values of $k_{3}$ and $k_{3}^{\prime}$ are nearly equal to these of $k_{3 \mathrm{~A}}^{\prime}$ and $k_{3 \mathrm{~B}}$, respectively ${ }^{5,8)}$. But in a reaction system containing radicals of greatly different character, a benzoylperoxy radical and a hydroperoxy radical, reaction rate of a radical with hydrocarbon and aldehyde may be considered to depend much on the character of a radical. In this case difference in the reactivities of the types of hydrogen atoms toward peroxy radicals is smaller than that in the reactivities of the two types of peroxy radicals toward hydrocarbon and aldehyde. The schematic potential curves are shown in

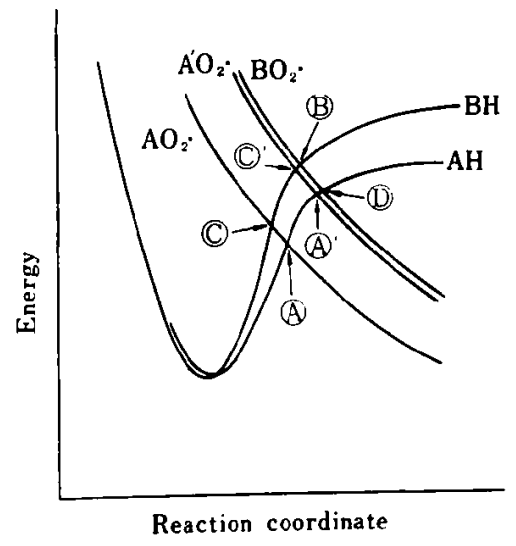

Fig. 5 Potential energy curve

Fig. 5 and the transition states of the reaction of the radicals of the similar reactivities corresponding to Eq. (10), (11), (12) and (13) are $\mathrm{A}^{\prime}, \mathrm{B}, \mathrm{C}^{\prime}$ and $\mathrm{D}$, respectively. However, in the case of the radicals of different reactivities, the transition states are $\mathrm{A}, \mathrm{B}, \mathrm{C}$ and $\mathrm{D}$. In the latter case, it is more reasonable to consider $k_{3 \mathrm{~A}}^{\prime} \doteqdot k_{3}^{\prime}$ and $k_{3 \mathrm{~B}}$ $\doteqdot k_{3}$ than $k_{3 \mathrm{~A}}^{\prime} \doteqdot k_{3}$ and $k_{3 \mathrm{~B}} \doteqdot k_{3}^{\prime}$. Our results correspond to the latter. From this speculation, we have assumed $k_{3 \mathrm{~A}}^{\prime}=k_{3}^{\prime}$ and $k_{3 \mathrm{~B}}=k_{3}$. The value of $k_{7}$ should be constant regardless of the concentration of reactant. The calculated values of $k_{7}$ are nearly constant. In other assumptions, that is, $k_{3 A}^{\prime}=k_{3}$ and $k_{3 \mathrm{~B}}=k_{3}^{\prime}$, or $k_{3 \mathrm{~A}}^{\prime}=k_{3}=k_{3 \mathrm{~B}}$, the calculated values of $k_{7}$ have been negative values, or have varied between $10^{8}$ and $10^{12}$ with the change of hydrocarbon concentration. Therefore, it may be concluded that our assumption is not gross in error.

At high concentrations of cumene, the absorption rate of oxygen increases more than a sum of the rate of cumene without benzaldehyde and benzaldehyde without cumene, shown by a dotted line in Fig. 4, unlike in the case of tetralin, shown by a dotted line in Fig. 3. A possible explanation for such a difference may be found in the fact that since $k_{1} \gg k_{1}^{\prime}$, a reaction is predominantly initiated by Eq. (6) in both cases, but cumylperoxy radical is produced readily by Eq. (12) and a rate constant for termination between cumylperoxy radicals is far smaller than that between benzoylperoxy radicals and that between tetralylperoxy radicals, therefore a reaction system at high concentra- 
tion of cumene is rich in cumylperoxy radical, and the chain length of cumene-benzaldehyde oxidation is longer than that of benzaldehyde without cumene, and tetralinbenzaldehyde.

Absorption rates of oxygen for the oxidation of tetralin-benzaldehyde mixture as well as of cumene-benzaldehyde in the low concentration of cumene are smaller than those of benzaldehyde without hydrocarbon. It may be explained as an increase in the rate of termination in the case of tetralin and as a low concentration of cumylperoxy radical in the case of cumene. The low concentration of cumylperoxy radical indicates that the influence of cross termination, Eq. (16), for the oxidation rate is larger than that between cumylperoxy radicals.

\section{Acknowledgement}

The authors wish to thank Professors Ikuzo Tanaka and Shin Sato for their helpful discussions, and Mr. Isamu Yamada for his technical assistance. One of the authors, T. I., also wishes to thank Tōyō Sōda Manufacturing Co., Ltd. for his financial support.

\section{References}

1) Brill, T. A., Ind. Eng. Chem., 52, 835 (1960).

2) Belg. P. 62303 (1963).

3) Ohta, N., J. Chem. Soc. Japan (Ind. Chem. Sect.), 67, 1100 (1964).

4) Walling, C., McElhill, E. A., J. Am. Chem. Soc., 73, 2927 (1951).

5) Russell, G. A., J. Am. Chem. Soc., 77, 4583 (1955); ibid., 78, 1047 (1956).

6) Ingles, T. A., Melville, H.W., Proc. Roy. Soc., 218, 163 (1953).

7) Alagy, M. J., Clément, G., Balacéanu, J.-C., Bull. Soc. Chim. France, 1325 (1959).

8) Thomas, J. R., Tolman, C. A., J. Am. Chem. Soc., 84, 2079 (1962).

9) Howard, J.A., Robb, J.C., Trans. Faraday Soc., 59, 1590 (1963).

10) Ingles, T. A., Melville, H.W., Proc. Roy. Soc., A218, 175 (1953).

11) Melville, H.W., Richards, S., J. Chem. Soc., 944 (1954).

12) Bamford, C. H., Dewar, M. J.S., Proc. Roy. Soc., A198, 252 (1949).

13) Water, W.A., Jones, C.W., J. Chem. Soc., 812 (1951).

14) Ogata, Y., Tabushi, I., Akimoto, H., J. Org. Chem., 26, 4803 (1961).

15) Kolthoff, I. M., Lee, T., Mairs, M. A., J. Polymer Sci., 2, 199 (1947). 